\title{
Knowledge, attitude, and practice of breast feeding mothers in a tertiary care centre: a descriptive study
}

\author{
Bindu A. ${ }^{1}$, Noushadali A. K. ${ }^{2}$, Kutty P. M. ${ }^{3}$ \\ ${ }^{1}$ Dr. Bindu A, Associate Professor, ${ }^{2}$ Dr. Noushadali A. K, Assistant Professor, ${ }^{3}$ Dr. Kutty P.M, Professor, all \\ authors are affiliated with MES Medical College, Perinthalmanna, Malappuram, Kerala, India.
}

Address for Correspondence: Dr. Noushadali A K, E-mail: binduathoor@yahoo.com

\begin{abstract}
Objective: Child feeding practices, including breastfeeding, affects the nutritional status of children under two years of age. Maternal knowledge and comfort of breastfeeding are factors that predict the feeding outcomes. The current study was designed to assess the knowledge, attitude, and practice regarding breastfeeding of mothers attending the outpatient department and Immunization clinic of a tertiary center in Kerala. Methods: This descriptive, cross-sectional study was conducted from August 2015 to October 2015. The study subjects included all eligible mothers with infants between 6 months to 1 year of age visiting the outpatient department and immunization clinic during the study period. Results: All participants had knowledge that child should be breastfed, but only $73 \%$ had knowledge about exclusive breastfeeding. In this study, more than half of the participants $(62.5 \%)$ initiated breastfeeding within one hour of delivery. Only one-third of the participants practiced exclusive breastfeeding for more than 6 months. Conclusion: The present study shows that breastfeeding behavior among the study population is still far from optimal.
\end{abstract}

Keywords: Breastfeeding, Child feeding, Breastfeeding practice, Child health

\section{Introduction}

Exclusive breastfeeding is very important for the health of both mother and the newborn. Exclusive breastfeeding for the first six months aids in optimal growth and development of the child. Mothers can continue breastfeeding for up to two years, while also giving nutritionally rich and safe supplementary foods. Studies show an increased risk of mortality due to diarrhea and other infections in children who are not breastfed or was partially breastfed [1].

Child feeding practices, including breastfeeding, affects the nutritional status of children under two years of age. In India,low nutritional status is one of the important cause of deaths in children under 2 years of age[2]. Over $15 \%$ of child deaths are associated with feeding practices, particularly in the first year of life of the child. Studies report that $13 \%$ of the deaths can be prevented by early and exclusive breastfeeding[3]. Poor feeding practices

Manuscript received: $14^{\text {th }}$ November 2017

Reviewed: $24^{\text {th }}$ November 2017

Author Corrected: $30^{\text {th }}$ November 2017

Accepted for Publication: $5^{\text {th }}$ December 2017 and poor attitude towards breastfeeding are some of the major reasons for poor nutritional outcome in children. Thus, appropriate and timely promotion of good practices and attitude are important, especially in countries with high disease burden.

Good breastfeeding practices may be affected by many social, cultural, and economic factors. Urbanization and employment of lactating mothers have led to a slight decline in breastfeeding practices. This is true in India too, as shown in a study conducted in Delhi [4]. Attitude of mothers towards breastfeeding influences breastfeeding practice, with negative attitude forming a barrier for the initiation and continuation of good feeding practices. For better success and continued breastfeeding practices among mothers, maternal positive attitude and knowledge are crucial.

Three basic strategies that can bring about a favorable change in the behavior of mothers towards feeding habits are information, education, and 
communication. Maternal knowledge and comfort of breastfeeding are factors that predict the feeding outcomes. In India, the main source of information for mothers still remain family and friends, and a structured counseling service on child feeding is lacking[5]. Promoting and protecting the good breastfeeding practices can indirectly benefit the nutritional status of children.

Awareness of the importance of good feeding attitude and practice can help in improving the overall behavior of thelactating mother. Inadequate support to the mothers may lead to premature cessation of breastfeeding. Education and support for breastfeeding are thus key for good practices. Education can be provided by doctors, nurses, midwives or counselors, particularly during prenatal period or immediately after delivery.

The support should be continued at home by mothers or family members to facilitate good breastfeeding practice. This is especially true of families belonging to low socioeconomic strata.

Appropriate support, both pre-natal and post-natal, can promote positive feeding outcomes, improved rates of exclusive breastfeeding, and better maternal-child bonding. A number of regional and social factors affect the perception and attitude of mothers towards good feeding practices.

Thus, studies assessing the different variables of a region are important for better understanding of the possible promotional interventions. This will help in developing a structured, comprehensive, and

\section{Results}

Sociodemographic characteristics- Two hundred eligible mothers participated in this observational study. Majority of the participants were in the age group of 20-30 years (68.5\%), were unemployed (87\%), were residing in Panchayath area (97\%), and hadsecondary level education (72\%). Sociodemographic characteristics of the participants in the study are given in Table 1.

Knowledge about breastfeeding- All 200 participants of the study (100\%) had knowledge that child should be breastfed, but only $73 \%$ had knowledge about exclusive breastfeeding. Regarding immediate initiation of breastfeeding after delivery, $55 \%$ of the participants responded that they were aware.

Majority of mothers had knowledge that night feeding is needed (81.5\%), and about the advantages of breastfeeding $(66 \%)$.

Regarding the need to give colostrum, only $46 \%$ were aware of it, while $54 \%$ did not know about it. About threefourths of the mothers in the study (73.5\%) did not know that prelacteal feed should be avoided, while $26.5 \%$ were aware. More than half of the participants (61.5\%) did not know about the dangers of bottle feeding (Table 2). 
Table-1: Sociodemographic characteristics of study participants.

\begin{tabular}{|c|c|c|}
\hline Characteristics & & Percentage \\
\hline \multirow{3}{*}{ Maternal age (years) } & $\leq 20$ & 10.5 \\
\hline & $21-30$ & 68.5 \\
\hline & $\geq 31$ & 21 \\
\hline \multirow{3}{*}{ Maternal education } & Primary & 7 \\
\hline & Secondary & 72 \\
\hline & Graduate & 21 \\
\hline \multirow{2}{*}{ Occupation of mother } & Employed & 13 \\
\hline & unemployed & 87 \\
\hline \multirow{2}{*}{ Residence } & Panchayath & 97 \\
\hline & Municipality & 3 \\
\hline \multirow{2}{*}{ Sex of the child } & Male & 58 \\
\hline & Female & 42 \\
\hline
\end{tabular}

Table-2: Knowledge of participants about breastfeeding.

\begin{tabular}{|c|c|c|c|c|}
\hline Maternal knowledge & \multicolumn{2}{|c|}{ Yes } & \multicolumn{2}{c|}{ No } \\
\hline Variable & Frequency & \% & Frequency & - \\
\hline Have to breastfeed & 200 & 100 & - & 45 \\
\hline $\begin{array}{c}\text { Initiation of breastfeeding in the 1st } \\
\text { hour after delivery }\end{array}$ & 110 & 55 & 90 & 27 \\
\hline About exclusive breastfeeding & 146 & 73 & 54 & 18.5 \\
\hline Need for night feeding & 163 & 81.5 & 68 & 34 \\
\hline Advantages of breastfeeding & 132 & 66 & 102 & 54 \\
\hline Colostrum should be given & 92 & 46 & 147 & 73.5 \\
\hline Prelacteal feed should be avoided & 53 & 26.5 & 133 & 61.5 \\
\hline Dangers of bottle feeding & 77 & 38.5 & & 68 \\
\hline
\end{tabular}

Breastfeeding practices among participants- In this study; more than half of the participants $(62.5 \%)$ initiated breastfeeding within one hour of delivery. Less than $20 \%$ of the mothers $(17.5 \%)$ started breastfeeding 4 hours after delivery. Onlyone-third of the participants practiced exclusive breastfeeding for more than 6 months.

About three-fourths of the participants in the study (74\%) had not given animal milk, while two-thirds had not resorted to any type of formula feeding to the child. Nearly all (99\%) of them gave prelacteal feeds to children. Only $15 \%$ of the respondents felt that breast milk was less or sufficient (Table: 3 )

There was nosignificant association betweentheeducational status of the mother and practice of exclusive breastfeeding $(0.84 ; \mathrm{p}<0.05)$. Similarly, theoccupation of the mother also did not have a significant relation with exclusive breastfeeding $(0.68, \mathrm{p}<0.05)$.

Attitude of participants towards breastfeeding- More than half of the respondents $(65 \%)$ believed in exclusive breastfeeding for their child.

Majority of mothers $(64 \%)$ were not comfortable to give any other feed other than breast milk for their children. But, a good percentage of the participants (54\%) did not consider colostrum as an important part of breastfeeding. Moreover, $73.5 \%$ did not think that prelacteal feed should be avoided. 
Table-3: Breastfeeding practices of the participants in the study.

\begin{tabular}{|c|c|c|}
\hline Breastfeeding Practice & Frequency & Percentage \\
\hline \multicolumn{3}{|l|}{ Initiation of breastfeeding } \\
\hline$<1$ hour & 125 & 62.5 \\
\hline 1-4 hours & 40 & 20 \\
\hline$>4$ hours & 35 & 17.5 \\
\hline \multicolumn{3}{|l|}{ Exclusive breastfeeding } \\
\hline$<6$ Months & 130 & 65 \\
\hline$>6$ Months & 70 & 35 \\
\hline \multicolumn{3}{|l|}{ Formula feeding } \\
\hline Given & 75 & 37 \\
\hline Not given & 125 & 64 \\
\hline \multicolumn{3}{|l|}{ Feeding of animal milk } \\
\hline Given & 52 & 26 \\
\hline Not given & 148 & 74 \\
\hline \multicolumn{3}{|l|}{ Pre-lacteal feeds } \\
\hline Given & 198 & 99 \\
\hline Not given & 2 & 1 \\
\hline \multicolumn{3}{|l|}{ Colostrum } \\
\hline Given & 194 & 97 \\
\hline Not given & 6 & 3 \\
\hline \multicolumn{3}{|l|}{ Feeling of less milk } \\
\hline Yes & 29 & 15 \\
\hline No & 171 & 85 \\
\hline
\end{tabular}

\section{Discussion}

This study investigated the knowledge, practices, and attitude regarding breastfeedingin mothers. All the respondents in the study had prior knowledge about breastfeeding andthemajority of them were aware of exclusive breastfeeding. As per the National family health survey, 53.3\% of the newborns in Kerala is exclusively breastfed [6]. The findings of our study are higher when compared to other studies [7-11]. But the percentage respondents is still lower when compared to the study conducted in a rural area in West Bengal[12].

Table-4: Breastfeeding practices in other studies.

\begin{tabular}{|c|c|c|c|c|c|c|c|}
\hline & $\begin{array}{c}\text { Curren } \\
\text { t study }\end{array}$ & $\begin{array}{c}\text { Chaudhuri } \\
\text { et al., 2011 } \\
\text { [7] }\end{array}$ & $\begin{array}{c}\text { Shaili et } \\
\text { al., 2012 } \\
\text { [8] }\end{array}$ & $\begin{array}{c}\text { Shashank } \\
\text { and Chethan, } \\
\mathbf{2 0 1 6}[\mathbf{1 1}]\end{array}$ & $\begin{array}{c}\text { Vijayalaksh } \\
\text { mi et al., } \\
\mathbf{2 0 1 5}[\mathbf{1 0}]\end{array}$ & $\begin{array}{c}\text { Chattopadh } \\
\text { yay et al., } \\
\mathbf{2 0 1 3}[\mathbf{1 2}]\end{array}$ & $\begin{array}{c}\text { Hiremat } \\
\text { h et al., } \\
\mathbf{2 0 1 3}[\mathbf{9}]\end{array}$ \\
\hline $\begin{array}{c}\text { Exclusive } \\
\text { breastfeeding }\end{array}$ & 35 & 23.5 & 5.13 & 32 & 27 & 58.7 & 27.1 \\
\hline $\begin{array}{c}\text { Initiation } \\
\text { within one } \\
\text { hour }\end{array}$ & 62.5 & 41.5 & 21.37 & 37.41 & 36.9 & 34.2 & 5.1 \\
\hline $\begin{array}{c}\text { Prelacteal } \\
\text { feeds }\end{array}$ & 99 & 10 & 61.8 & 29.5 & Not recorded & 42.1 & 66.1 \\
\hline $\begin{array}{c}\text { Colostrum } \\
\text { feeding }\end{array}$ & 97 & 95 & 87.18 & 76.61 & 96.7 & 76.3 & 72 \\
\hline
\end{tabular}


Table 4 gives a comparison of values from different studies. The current study shows $35 \%$ of the children to be exclusively breastfed, although $73 \%$ of the respondents had knowledge of this practice. This difference in knowledge and practice has been reported in other studies from India and abroad[10].Exclusive breastfeeding, though practiced, was not continued for more than six months in many cases[13,14].

These stresses the importance of counseling in ante-natal care for better practices in feeding newborns. Ante-natal care and adviceareequally important in preparing and continuing exclusive breastfeeding for more than six months. Studies report a low prevalence of exclusive breastfeeding at six months in some low resource countries $[15,16]$.

Studies from developing countries show that lactating mothers are knowledgeable about exclusive breastfeeding $[17,18]$. Most of the mothers agree that breastfeeding should be continued until the age of 2 years. A study from India reported that mothers had a low attitude score towards some of the variables like lack of iron in breastmilk, and increased chances of overfeeding with formula feeding[10]. Promotional interventions that focus on improving breastfeeding practices should also hit upon these attitudes for better penetration.

World Health Organization (WHO) recommends breastfeedingto be initiated, preferably, within half an hour of delivery[19]. Early initiation is known to boost oxytocin reflexes which in turn will improve breast milk reflex. In the India, the rate of early breastfeeding initiation ranges from $16 \%-54.5 \%$ [20].Among the respondents in the current study, though $55 \%$ perceived initiation within an hour of delivery to be good, a higher percentage $(62.5 \%)$ actually practiced early initiation. This is higher than other comparative studies mentioned in Table 4.

A study conducted in India observed delay in shifting mothers from labor room, Caesarean section, family restrictions and babies being in neonatal ICU as the main reasons for not initiating breastfeeding earlier[10]. Increasing the awareness about initiating breastfeeding early will go a long way in improving this practice among mothers.

About $35 \%$ of the respondents in the current study started supplementary feed before six months. Some of the reasons for this may be the feeling of insufficient milk production and the belief that breast milk alone is inadequate for the growth of the child. Insufficient milk supply is reported as the main reason for women to startthe supplementary feed $[10,21]$. Promotional interventions for improving breastfeeding practices will help in changing the present attitude and behavior. Studies have shown that such interventions can enhance the rate of exclusive breastfeeding by six-fold[22].

Maternal knowledge and education are considered to be one of the determinant factors in good breastfeeding practices[23].About three-fourths of the respondents were educated to secondary level and had minimal knowledge gap with respect to breastfeeding.But nearly all (99\%) of them gave prelacteal feeds to children. This is quite alarming, considering the fact that it cannot be attributed to lack of literacy among mothers. Customs, traditional practice in the region and relative's advice may be the factors leading to thehigh percentage of prelacteal feeding. Another study from India did report illiterate lactating mothers as having abetter positive attitude towards breastfeeding when compared to literate mothers[10]. Similar results were obtained from Jordan, where women with higher education level were less likely to breastfeed when compared to less educated and illiterate mothers[24]. This result is important from an awareness point of view as apositive attitude is directly correlated to optimal exclusive breastfeeding practice among mothers[25].It shows that ante-natal counseling plays an important role in channelizing mothers toward better breastfeedingpractices.

A total of $92(46 \%)$ respondents perceived that giving colostrum to be a good practice, though a higher percentage $(97 \%)$ actually gave colostrum to the newborn. This is on par or higher than the values given in other comparative studies (Table 4). A larger sample size would enable generalization of the results. More studies with large sample size and qualitative factors will help in identifying the barriers that hinder optimal breastfeeding practices among lactating mothers. Studies should also focus on the perceptions of the post-natal healthcare providers to throw light on the cultural and social belief systems that affect newborn feeding. 


\section{Conclusions}

Most of the respondents in our study had good knowledge and positive attitude towards breastfeeding. But the knowledge should be treated with caution as appropriate practice is still low. The present study shows that breastfeeding behavior among the study population is still far from optimal.

National strategy components forthe support ofbreastfeeding in terms of early initiationduring thefirst hour and implementing the baby-friendly hospital initiative has to be reinforced strongly in the region. This will require greater involvement from obstetricians and Accredited Social Health Activist (ASHA) workers.

What this study adds to existing knowledge- The present study shows that even when the maternal population has knowledge and attitude, special attention has to be given to the practice of breastfeeding. The region lacks optimal breastfeeding behavior and care should be taken to reinforce the strategy. Ante-natal care, counseling, and advice are important in preparing the expectant moms for the best practices in feeding newborns.

Contribution by authors: All authors participated in conceptualizing the study. Bindu developed the analytical plan, analyzed the data,searched literature and drafted and revised the manuscript.

Noushadaliinterpreted the data and edited and revised the manuscript. All authors approved the final manuscript.

Funding: Nil, Conflict of interest: None initiated, Perission from IRB: Yes

\section{References}

1. WHO. Indicators for assessing infant and young child feeding pratice part 3. WHO, Geneva; 2010.

2. Gupta A, Arora V, Bhatt B. The State of World's Breastfeeding: India Report card 2006. International Baby Food Action Network (IBFAN), Asia Pacific. India. 2006.

3. CARE. Infant and Young Child Feeding Practices: Collecting and Using Data: A Step-byStep Guide: Cooperative for Assistance and Relief Everywhere, Inc. [CARE]; 2010.
4. Rasania SK, Singh SK, Pathi S, Bhalla S, Sachdev TR. Breast-Feeding Practices in A Maternal and Child Health Centre In Delhi. Health PopulPerspect Issues. 2003; 26:110-5. Available at: http:// medind. nic.in/hab/t03/i3/habt03i3p110.pdf Accessed: $3^{\text {rd }}$ December, 2017.

5. Dadhich JP, Gupta A. Assessment of Status of Infant and Young Child Feeding (IYCF) practice, policy and program-Achievements and Gaps. Breastfeedingpro-motion network of India. 2005.

6. Government of India. National fact sheet India: 2015-2016 National family health survey (NFHS-3). State Fact Sheet, Kerala. New Delhi: Ministry of health and family Welfare, Govt.of India [Internet]; 2016. Available from: http://rchiips.org/nfhs/ [cited 2017 Oct 24].

7. Chaudhary R N, Shah T, and Raja S. Knowledge and practice of mothers regarding breastfeeding: a hospital based study. Health Renaissance. 2011; 9(3):194-200. doi: http://dx.doi.org/10.3126/ hren. v9i3.5590

8. Shaili V, Parul S, Kandpal S D, Jayanti S, Anurag S, Vipul N. A community based study on breastfeeding practices in rural areas of Uttarakhand. National Journal of Community Medicine. 2012; 3(2): 283-287.

9. Hiremath B R, Sorganvi V. A Cross-Sectional Study On Breastfeeding Practices In A Rural Area Of North Karnataka. IJCRR. 2013; 5(21): 13-18.

10. Vijayalakshmi P, Susheela T, Mythili D. Knowledge, attitudes, and breastfeeding practices of postnatal mothers: A cross sectional survey. Int J Health Sci (Qassim). 2015 Oct; 9(4): 364-374. PMCID: PMC4682591

11. Shashank K J and Chethan TK. A study of breastfeeding practices among mothers in rural area of Mangalore district: A cross-sectional study. National Journal of Community Medicine. 2016;7 (2): 134-137. pISSN 09763325

12. Chattopadhyay ND, Chakraborty S, Dasgupta A. Infant and young child feeding practices among mothers in a rural area of West Bengal, India. 
Annals of Medical and Health Sciences Research. 2013; 3(3): 370-375.

13. Tiwari R, Mahajan PC, Lahariya C. The determinants of exclusive breast feeding in urban slums: a community based study. J Trop Pediatr. 2009 Feb;55(1): 49-54. doi: 10.1093/tropej/fmn037. Epub 2008 May 22.

14. Bandyopadhyay M. Impact of ritualpollution on lactation and breastfeeding practices in rural West Bengal, India. Int Breastfeed J.2009Mar26;4:2. doi: 10. 1186/1746-4358-4-2.

15. Ulak M, Chandyo RK, Mellander L, Shrestha PS, Strand TA. Infant feeding practices in Bhaktapur, Nepal: a cross-sectional, health facility based survey. Int Breastfeed J. 2012 Jan 10; 7(1):1. doi: 10.1186/1746-4358-7-1.

16. Madhu K, Chowdary S, Masthi R. Breast feeding practices and newborn care in rural areas: a descriptive cross-sectional study. Indian J Community Med. 2009 Jul; 34 (3): 243-6. doi: 10. 4103/ 0970-0218.55292.

17. Oche MO, Umar AS, Ahmed H. Knowledge and practice of exclusive breastfeeding in Kware, Nigeria. Afr Health Sci. 2011 Sep;11(3):518-23.

18. Ekanem IA, Ekanem AP, Asuquo A, Eyo VO. Attitude of working mothers to exclusive breastfeeding in Calabar municipality, cross river State, Nigeria. Journal of Food Research. 2012;1: 71-75. Doi: 10.5539/jfr.v1n2p71.

19. World Health Organization, UNICEF. Ten steps to promote successful breastfeeding. Protecting, promotingand supporting breast-feeding: The special role of maternity services. Geneva: Mother and Child Division; 1989. p. iv.

\section{Original Research Article}

20. Agarwal S, Srivastava K, Sethi V. Maternal and New-born Care Practices Among the Urban Poor in Indore, India: Gaps, Reasons and Possible Program Options. Urban Health Resource Center; New Delhi: 2007.

21. Otsuka K, Dennis CL, Tatsuoka H, Jimba M. The relationship between breastfeeding self-efficacy and perceived insufficient milk among Japanese mothers. J ObstetGynecol Neonatal Nurs. 2008 SepOct;37(5):546-55. doi: 10.1111/j.1552-6909.2008. 00277.x

22. Imdad A, Yakoob MY, Bhutta ZA. Effect of breastfeeding promotion interventions on breastfeeding rates, with special focus on developing countries. BMC Public Health. 2011 Apr 13;11 Suppl3:S24. doi: 10.1186/1471-2458-11-S3S24.

23. Dubois L, Girard M. Social determinants of initiation, duration and exclusivity of breastfeeding at the population level: the results of the Longitudinal Study of Child Development in Quebec (ELDEQ 1998-2002). Can J Public Health. 2003 Jul-Aug;94(4):300-5.

24. Khassawneh M, Khader Y, Amarin Z, Alkafajei A. Knowledge, attitude and practice of breastfeeding in the north of Jordan: a cross-sectional study. Int Breastfeed J. 2006 Sep 23;1:17.

25. Hurley KM, Black MM, Papas MA, Quigg AM. Variation in breastfeeding behaviours, perceptions, and experiences by race/ethnicity among a lowincome statewide sample of Special Supplemental Nutrition Program for Women, Infants, and Children (WIC) participants in the United States. Matern Child Nutr. 2008 Apr;4(2):95-105. doi: 10.1111/j. 1740-8709.2007.00105.x.

\section{How to cite this article?}

Bindu A, Noushadali A. K, Kutty P. M.Knowledge, attitude, and practice of breast feeding mothers in a tertiary care centre: a descriptive study. Int J Pediatr Res. 2017;4(12):706-712.doi:10. 17511/ijpr.2017.i12.02. 